\title{
COVID-19 cases, hospitalizations and deaths in Belgian nursing homes: results of a surveillance conducted between April and December 2020
}

Eline Vandael ${ }^{1}$, Katrien Latour', Esma Islamaj ${ }^{1}$, Laura Int Panis ${ }^{1}$, Milena Callies ${ }^{1}$, Freek Haarhuis ${ }^{1}$, Kristiaan Proesmans ${ }^{1}$, Brecht Devleesschauwer ${ }^{1,2}$, Javiera Rebolledo Gonzalez ${ }^{1}$, Alice Hannecart ${ }^{1}$, Romain Mahieu ${ }^{3}$, Louise de Viron ${ }^{3}$, Etienne De Clercq $^{4}$, Anne Kongs ${ }^{5}$, Naïma Hammami ${ }^{6}$, Jean-Marc François ${ }^{7}$, Dominique Dubourg ${ }^{7}$, Sarah Henz ${ }^{8}$, Boudewijn Catry ${ }^{1,9}$ and Sara Dequeker ${ }^{1 *}$ (D)

\begin{abstract}
Background: In Belgium, the first COVID-19 death was reported on 10 March 2020. Nursing home (NH) residents are particularly vulnerable for COVID-19, making it essential to follow-up the spread of COVID-19 in this setting. This manuscript describes the methodology of surveillance and epidemiology of COVID-19 cases, hospitalizations and deaths in Belgian NHs.

Methods: A COVID-19 surveillance in all Belgian NHs $(n=1542)$ was set up by the regional health authorities and Sciensano. Aggregated data on possible/confirmed COVID-19 cases and hospitalizations and case-based data on deaths were reported by NHs at least once a week. The study period covered April-December 2020. Weekly incidence/prevalence data were calculated per 1000 residents or staff members.

Results: This surveillance has been launched within 14 days after the first COVID-19 death in Belgium. Automatic data cleaning was installed using different validation rules. More than $99 \%$ of NHs participated at least once, with a median weekly participation rate of 95\%. The cumulative incidence of possible/confirmed COVID-19 cases among residents was 206/1000 in the first wave and 367/1000 in the second wave. Most NHs (82\%) reported cases in both waves and $74 \%$ registered $\geq 10$ possible/confirmed cases among residents at one point in time. In $51 \%$ of NHs, at least 10\% of staff was absent due to COVID-19 at one point. Between 11 March 2020 and 3 January 2021, 11,329 COVID-19 deaths among NH residents were reported, comprising 57\% of all COVID-19 deaths in Belgium in that period.
\end{abstract}

\footnotetext{
* Correspondence: Sara.Dequeker@sciensano.be

'Department of Epidemiology and public health, Sciensano, Brussels, Belgium

Full list of author information is available at the end of the article
}

(c) The Author(s). 2022 Open Access This article is licensed under a Creative Commons Attribution 4.0 International License, which permits use, sharing, adaptation, distribution and reproduction in any medium or format, as long as you give appropriate credit to the original author(s) and the source, provide a link to the Creative Commons licence, and indicate if changes were made. The images or other third party material in this article are included in the article's Creative Commons licence, unless indicated otherwise in a credit line to the material. If material is not included in the article's Creative Commons licence and your intended use is not permitted by statutory regulation or exceeds the permitted use, you will need to obtain permission directly from the copyright holder. To view a copy of this licence, visit http://creativecommons.org/licenses/by/4.0/ The Creative Commons Public Domain Dedication waiver (http://creativecommons.org/publicdomain/zero/1.0/) applies to the data made available in this article, unless otherwise stated in a credit line to the data. 
Conclusions: This surveillance was crucial in mapping COVID-19 in this vulnerable setting and guiding public health interventions, despite limitations of aggregated data and necessary changes in protocol over time. Belgian $\mathrm{NH}$ s were severely hit by COVID-19 with many fatal cases. The measure of not allowing visitors, implemented in the beginning of the pandemic, could not avoid the spread of SARS-CoV-2 in the NHs during the first wave. The virus was probably often introduced by staff. Once the virus was introduced, it was difficult to prevent healthcareassociated outbreaks. Although, in contrast to the first wave, personal protective equipment was available in the second wave, again a high number of cases were reported.

Keywords: COVID-19, Nursing homes, Surveillance, Epidemiology, Belgium

\section{Background}

The SARS-CoV-2 virus (severe acute respiratory syndrome coronavirus-2) had spread rapidly across the world with almost 93 million confirmed cases in 190 countries and nearly two million deaths at the beginning of 2021 [1]. In Belgium, the first COVID-19 case was reported in February 2020 and on 10 March 2020, the first COVID-19 death was confirmed [2]. As reported in other countries [3,4], older adults ( 65 years and older) were the most affected age group, representing $94 \%$ of all Belgian COVID-19 deaths between 10 March 2020 and 14 February 2021 [5]. Belgium was ranked among the countries with the highest COVID-19 mortality in the world during its first COVID-19 wave [6, 7]. Based on the cumulative results on the COVID-19 dashboard of the European Centre for Disease Prevention and Control (ECDC) on the 3rd of January 2021, Belgium ranked on the second place among European countries with 1735 COVID-19 deaths per million population. When looking at the number of cases, Belgium stood on the 10th place with 5691 COVID-19 cases per million population [8]. However, differences in reporting practice should be taken into account when comparing countries.

Similar to other European countries, Belgium has an aging population with approximately $19 \%$ of the population older than 65 years. Of the latter group, 5.7\% is living in nursing homes for elderly (NHs) [9]. Belgium has one of the highest number of $\mathrm{NH}$ beds per 1000 population in Europe and tops the chart with the number of people of 85 years and older living in an institution [10].

Globally, the pandemic has been catastrophic for many NHs [11], and the Belgian institutions are no exception. Due to their advanced age and the high prevalence of comorbidities, $\mathrm{NH}$ residents are extra vulnerable to communicable diseases, COVID-19 in particular. Moreover, they have frequent close contacts with caregivers and other residents [12, 13], leading to a high risk of widespread transmission and outbreaks of viruses, such as SARS-CoV-2. Staff members and visitors, who daily interchange between the $\mathrm{NH}$ and the community, can easily introduce the virus in the $\mathrm{NH}$ [14]. Because of the combination of high vulnerability and outbreak-potential, it was essential to follow-up the spread of COVID-19 in these settings.
In March 2020, immediately after the first Belgian COVID-19 cases were reported, surveillance systems were set up, not only to follow-up the COVID-19 situation among the general population, but also among $\mathrm{NH}$ residents and the concerned healthcare workers. In May 2020, ECDC recommended the implementation of local and national monitoring systems for COVID-19 in longterm care facilities (LTCFs) such as NHs [15].

The aim of this manuscript is to describe the methodology of the COVID-19 surveillance in Belgian NHs during the study period (April-December 2020) as well as the epidemiology of the reported cases (residents and staff), hospitalizations (residents) and deaths (residents) due to COVID-19 in these NHs prior to the start of the vaccination campaign (5th of January 2021).

\section{Methods}

Data collection

Since NHs fall under the responsibility of the federated entities, the COVID-19 surveillance in NHs was organized by the regional health authorities (RHA). Each RHA collected the data, analysed them and organised interventions accordingly on a daily basis. The data of all regions were merged in one database and analysed at national level by Sciensano, the Belgian institute for health. More details of the different regional data collection tools and methods can be found in Additional file 1.

All Belgian NHs $(n=1542)$ were invited to participate in the surveillance. Although strongly encouraged and being contacted in case of non-participation by the RHA, the number of NHs that reported data varied. The surveillance started in March 2020 and was initially based on a daily collection of aggregated data reported by $\mathrm{NH}$ staff. Since early July, NHs (except for Flanders) were asked to report at least once a week (preferably on Tuesday) in case of zero reporting. Any changes (e.g. new COVID-19 cases, change in the prevalence) had to be reported immediately (see Additional file 1). Collected variables and applied definitions can be found in Tables 1 and 2, respectively.

\section{Data analyses}

Data until 3 January 2021 (week 53 of 2020) were used for the analyses. Automatic data cleaning was performed 
Table 1 Collected variables in the COVID-19 surveillance in Belgian nursing homes [16]

\begin{tabular}{|c|c|}
\hline \multicolumn{2}{|l|}{ Date of registration } \\
\hline $\mathrm{NH}^{\mathrm{a}}$ characteristics & $\begin{array}{l}\text { - Name } \\
\text { - Unique identification number } \\
\text { - Postal code } \\
\text { - Number of beds } \\
\text { - Number of occupied beds (including beds occupied by hospitalized residents and short-stay residents), } \\
\text { - Number of staff }\end{array}$ \\
\hline $\begin{array}{l}\text { Residents with confirmed or possible } \\
\text { COVID-19 infection }\end{array}$ & $\begin{array}{l}\text { - Number of newly reported confirmed/possible COVID-19 cases since the last reporting } \\
\text { - Total number of confirmed/possible COVID-19 cases at the moment of registration }\end{array}$ \\
\hline $\begin{array}{l}\text { Hospitalizations of residents due to } \\
\text { COVID-19 }\end{array}$ & $\begin{array}{l}\text { - Number of newly reported confirmed/possible COVID-19 cases admitted to a hospital since the last } \\
\text { reporting }\end{array}$ \\
\hline COVID-19 deaths among residents ${ }^{c}$ & $\begin{array}{l}\text { Case-based data of deceased residents } \\
\text { - Date of birth } \\
\text { - Date of death } \\
\text { - Gender } \\
\text { - Method of diagnosis (lab-confirmed, computed tomography (CT thorax) confirmed, possible) } \\
\text { - Place of death (NH, hospital, other) }\end{array}$ \\
\hline $\begin{array}{l}\text { Staff }{ }^{b} \text { with confirmed or possible } \\
\text { COVID-19 infections }\end{array}$ & $\begin{array}{l}\text { - Number of newly reported confirmed/possible COVID-19 cases since the last reporting } \\
\text { - Total number of confirmed/possible COVID-19 cases absent from work at the moment of registration } \\
\text { (available since } 12 \text { May } 2020 \text { for all regions) }\end{array}$ \\
\hline
\end{tabular}

${ }^{a}$ Nursing homes (NHs) in Belgium can be defined as collective residences in which mainly older people, with different levels of disabilities and independence, are living on a long-term basis (usually until the end of their life). NHs offer a home substitute environment when care can no longer be adequately provided at home or with a short-term admission in a residential institution $[17,18]$

${ }^{b}$ All personnel working in the facility, including nursing staff, paramedical staff, animation team, staff concerned with cleaning, maintenance or quality control, and $\mathrm{NH}$ managers and their administrative staff, but excluding students and volunteers

${ }^{\mathrm{c}}$ More information on the methodology of the COVID-19 death surveillance can be found in Renard et al. [7]

using different validation rules. Aberrant values were set to missing in the database. More information on the data cleaning process can be found in Additional file 2.

Data were divided in three periods: the first wave (W1, 30 March 2020 to 21 June 2020, week 14-25; for data on COVID-deaths: starting on 11 March (week 11)), an interwave period (22 June 2020 to 30 August 2020, week 26-35), and the second wave (W2, start date: 31 August 2020 , week 36). These waves were defined based on the number of COVID-19 cases in the Belgian general population. W1 started earlier than the end of March, but valid data was only available since the end of March. W2 lasted longer than the end of December but as vaccination campaigns started in January 2021 in Belgian NHs, 3 January 2021 (week 53) was used as end date for the present paper.

Analyses were performed on the number of (new) COVID-19 cases among residents and staff, the number of newly reported hospitalizations related to COVID-19 among residents and the number of COVID-19 deaths among residents. The sum of the number of possible and confirmed COVID-19 cases was used in the analyses, as testing was not yet possible in the beginning of the study period in NHs (reserved for hospitalized patients only). In addition, specific results for confirmed COVID-19 cases only are also shown for the interwave period and W2.

Incidence data were presented as the sum per week of newly reported possible and confirmed cases per 1000 $\mathrm{NH}$ residents or staff members. Prevalence data were presented as the total number of reported possible or confirmed cases at the moment of registration per 1000 $\mathrm{NH}$ residents or staff members. As the participation rate was overall the highest on Tuesdays (as since 1 July, NHs were conveniently asked in certain regions to report at least once a week on Tuesday), weekly prevalence data were estimated based on data of Tuesday (or Wednesday if Tuesday was a public holiday). Weeks are always displayed from Monday to Sunday. Both crude overall prevalence and incidence rates (total number of (new) cases over the total number of residents or staff in all $\mathrm{NHs}$ ) and prevalence and incidence rates per $\mathrm{NH}$ were calculated.

The number of occupied beds at the moment of reporting was used as denominator for the total number of residents (or number of beds if not available). To have one denominator per $\mathrm{NH}$, the median bed occupation per $\mathrm{NH}$ was used for the period of analysis (per week, wave or total study period). For staff, a fixed number at the beginning of the crisis was used (first entry between March-May 2020). To correct for varying participation rates, only $\mathrm{NHs}$ that reported data during the concerned time period were taken into account in the denominator. NHs with missing data for a certain variable were excluded in the analyses of that particular variable (both in the numerator and denominator).

Deaths among NH residents that were due to a clinically compatible disease are included in the analysis, regardless of the type of COVID-19 classification (laboratory molecular test, radiologically confirmed case, 
Table 2 Applied definitions in the COVID-19 surveillance in Belgian nursing homes (NHs) [19]

\begin{tabular}{|c|c|}
\hline \multicolumn{2}{|c|}{ Confirmed COVID-19 case } \\
\hline $\begin{array}{l}\text { Before } 12 \\
\text { May } 2020\end{array}$ & $\begin{array}{l}\text { Person with laboratory confirmation of SARS- } \\
\text { CoV-2, irrespective of clinical signs and } \\
\text { symptoms. }\end{array}$ \\
\hline $\begin{array}{l}\text { Since } 12 \text { May } \\
2020\end{array}$ & $\begin{array}{l}\text { Person with laboratory confirmation of SARS-CoV-2 } \\
\text { via a molecular test (polymerase chain reaction (PCR) } \\
\text { or rapid antigen test), irrespective of clinical signs } \\
\text { and symptoms. A symptomatic confirmed case stays } \\
\text { a confirmed case until } 14 \text { days after the onset of } \\
\text { signs/symptoms AND with at least } 3 \text { days without } \\
\text { fever AND with a significant improvement in respira- } \\
\text { tory symptoms. An asymptomatic confirmed case } \\
\text { stays a confirmed case until } 14 \text { days after the positive } \\
\text { test. If the resident has a negative laboratory test } \\
\text { within this time span, he/she remains a confirmed } \\
\text { case. }\end{array}$ \\
\hline \multicolumn{2}{|c|}{ Possible COVID-19 case } \\
\hline $\begin{array}{l}\text { Before } 12 \text { May } \\
2020\end{array}$ & $\begin{array}{l}\text { Person with an acute upper or lower respiratory tract } \\
\text { infection not present before OR who deteriorated if } \\
\text { the patient shows chronic respiratory symptoms. }\end{array}$ \\
\hline $\begin{array}{l}\text { Since } 12 \text { May } \\
2020\end{array}$ & $\begin{array}{l}\text { Person } \\
\text { - with at least one of the following main signs/ } \\
\text { symptoms of an acute viral infection: cough, } \\
\text { dyspnoea (shortness of breath), thoracic pain, acute } \\
\text { anosmia (loss of the sense of smell) or dysgeusia } \\
\text { (distortion of the sense of taste) without obvious } \\
\text { cause; } \\
\text { OR } \\
\text { - with at least two of the following signs/symptoms: } \\
\text { fever, muscle pain, fatigue, rhinitis, sore throat, } \\
\text { headache, anorexia, watery diarrhoea with no } \\
\text { obvious cause, acute confusion, sudden fall with } \\
\text { no obvious cause; } \\
\text { OR } \\
\text { - with worsening of chronic respiratory symptoms } \\
\text { (chronic obstructive pulmonary disease, asthma, } \\
\text { chronic cough,...); } \\
\text { OR } \\
\text { - who did not have a laboratory test or whose } \\
\text { laboratory test is negative, but who is diagnosed } \\
\text { with COVID-19 based on a suggestive clinical pres- } \\
\text { entation and a compatible computed tomography } \\
\text { (CT) thorax. }\end{array}$ \\
\hline
\end{tabular}

and by means of clinical criteria) [7]. For hospital deaths between 13 March 2020 and April 2020 information about the residence (whether it concerned a $\mathrm{NH}$ resident or not) was not available for Flanders. The number of COVID-19 deaths of $\mathrm{NH}$ residents that died in a hospital in this period were therefore estimated using a correction factor. These estimations were excluded in the analyses of age/gender distribution of deceased residents and the distribution of the number of COVID-19 deaths per $\mathrm{NH}$. In the latter analysis, deaths that occurred in hospitals that could not be linked to a specific $\mathrm{NH}$ were excluded from the analysis.

Data cleaning and analyses were performed using SAS Enterprise version 7.1. Cumulative numbers, percentages, and medians with interquartile range (IQR) were calculated where appropriate. The number of NHs that reported at least one, two (possible cluster) or ten (possible large outbreak) COVID-19 cases among residents and absenteeism of staff due to COVID-19 (at least 10, 20 or $50 \%$ absent) were based on prevalence data. The number of NHs that never declared a COVID-19 case among staff was based on the cumulative incidence (as prevalence data are only available for staff absent from work).

\section{Results}

\section{COVID-19 infections among residents and staff}

Overall, $1529 \mathrm{NHs}$ out of 1542 (99\%; median number of beds: 91, IQR: 64-120) participated at least once during the complete study period, with a median weekly participation rate (NHs that participated at least once a week) of 95\% (IQR: 93-96\%). More details on the participation rate can be found in Additional file 3.

Figure 1 presents the incidence of COVID-19 cases among $\mathrm{NH}$ residents and staff members by week. In Fig. 2, the prevalence of COVID-19 cases is presented for both groups (staff: only cases absent from work). During W1, the peak of the crude incidence per week of possible or confirmed COVID-19 cases among residents (50 cases/1000 residents) was reached in week 15 (week of 6 April 2020). The crude prevalence was the highest on 21 April 2020 (80 cases/1000 residents). For staff, the peak was likely already reached before the data collection had started in all regions. During W2, the peak of the incidence was reached in week 44 (week of 26 October 2020) for both residents (55 cases/1000 residents) and staff members (42 cases/1000 staff members). The highest prevalence was reported on 10 November 2020 for residents (85 cases/1000 residents) and on 3 November 2020 for absent staff members (46 cases/1000 staff members).

The cumulative incidence of possible or confirmed COVID-19 cases at the end of W1 ( $n=951$ NHs, excluding NHs in Wallonia as incidence data were only available from 12 May 2020 onwards in this region) was 206/ 1000 residents (median per $\mathrm{NH}$ : 105/1000 residents, IQR: $30-290 / 1000$ residents) and 139/1000 staff members (median per NH: 81/1000 staff members, IQR: 29$201 / 1000$ staff members). For W2, the cumulative incidence was 367/1000 residents (median per NH: 196/ 1000 residents, IQR: 51-532/1000 residents) and 284/ 1000 staff members (median per NH: 194/1000 staff members, IQR: 81-396/1000 staff members). During $\mathrm{W} 2$, the cumulative incidence of confirmed cases only was 219/1000 residents (median per NH: 91/1000 residents, IQR: $10-349 / 1000$ residents) and 123/1000 staff members (median per NH: 61/1000 staff members, IQR: 13-165/1000 staff members).

In Fig. 3, the percentage of NHs that declared at least one, two and ten possible or confirmed COVID-19 cases among 


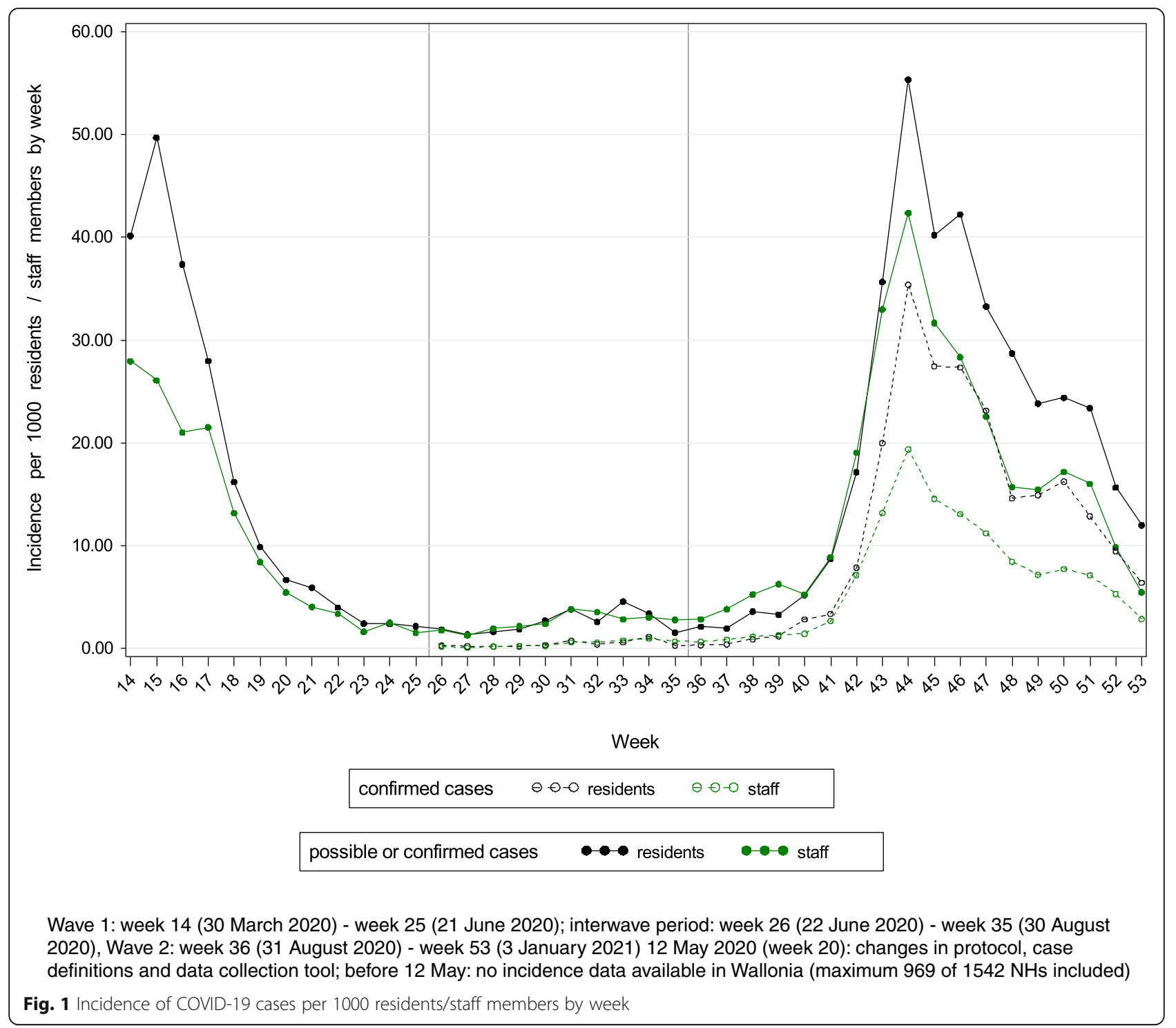

residents is displayed per week (on Tuesdays). Of all participating NHs, 97, 94 and 74\% reported respectively at least one, at least two and at least ten possible or confirmed COVID-19 cases among residents at one point in time (Table 3). Of the $603 \mathrm{NHs}$ that reported at least ten cases during W1, 565 (94\%) reported again at least one case and $250(42 \%)$ at least ten cases during W2.

Since 12 May, in 784 (51\%), $314(20 \%)$ and 38 (2.5\%) NHs respectively at least 10,20 and $50 \%$ of staff was absent due to (possible or confirmed) COVID-19 at one point in time. Only $62 \mathrm{NHs}(4.0 \%)$ never declared a possible or confirmed COVID-19 case among staff during the study period (W1: $n=128(13 \%)$; interwave period: $n=924(60 \%)$; W2: $n=114(7.4 \%))$. During W1 and W2, respectively $85(8.8 \%)$ and $67(4.3 \%) \mathrm{NHs}$ reported at least one possible or confirmed COVID-19 case among residents (spread over the weeks), but no possible or confirmed cases among staff.

\section{Hospitalizations of nursing home residents due to COVID-19}

Figure 4 displays the incidence of hospitalizations due to possible or confirmed COVID-19 infections per 1000 residents by week. The cumulative incidence of hospitalizations due to (possible or confirmed) COVID-19 infections was 22/1000 residents (median per NH: 8.9/1000 residents, IQR: 0-29/1000 residents) at the end of W1 $(n=950 \mathrm{NHs})$. For W2, this cumulative incidence was 29/1000 residents (median per NH: 11/1000 residents, IQR: $0-39 / 1000$ residents) $(n=1518)$. During W1 and W2, respectively 535 (55\%) and 875 (57\%) NHs reported at least one hospitalization of a resident due to (possible or confirmed) COVID-19. 


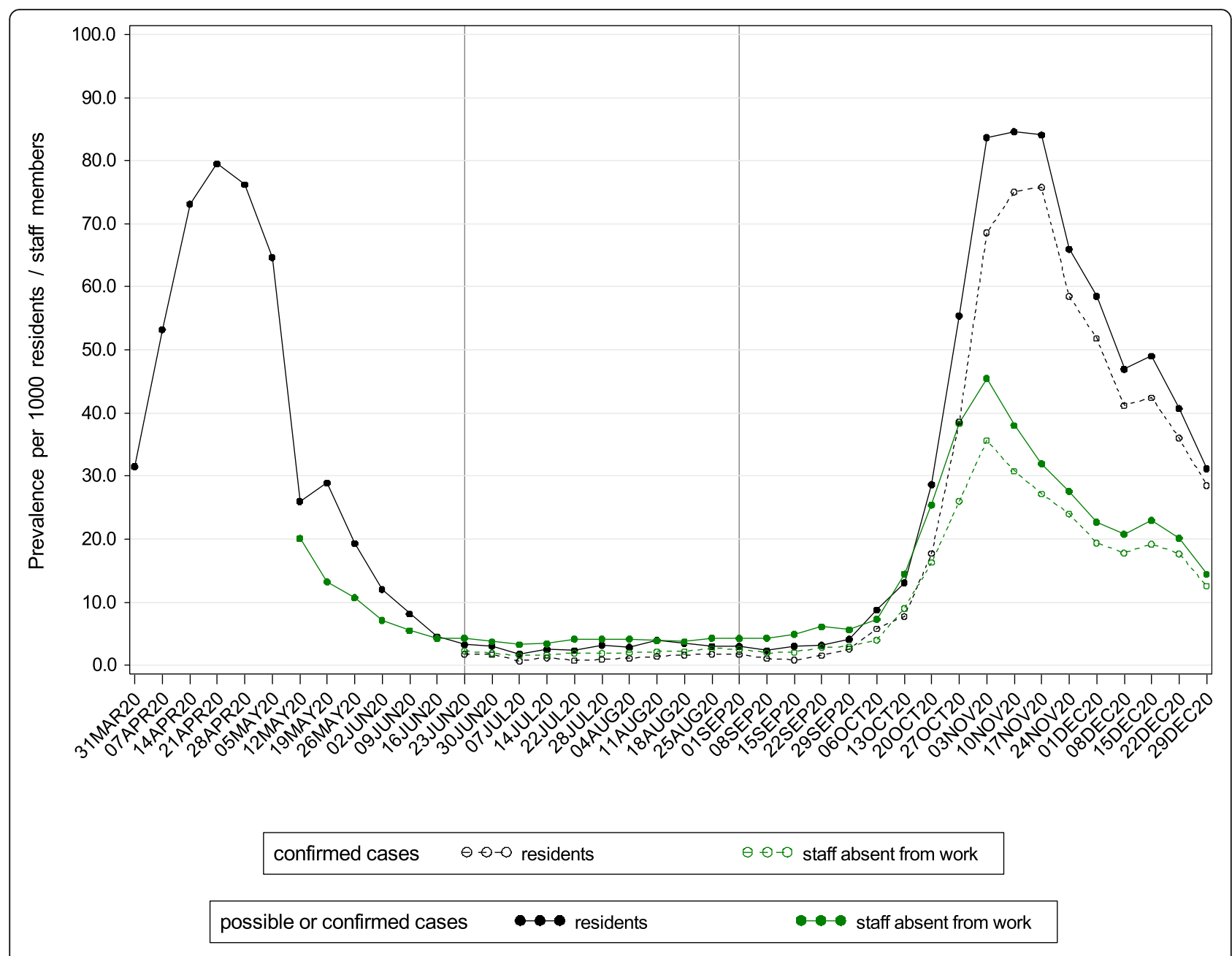

Prevalence is estimated based on data of Tuesday. Wave 1: week 14 (30 March 2020) - week 25 (21 June 2020); interwave period: week 26 (22 June 2020) - week 35 (30 August 2020), Wave 2: week 36 (31 August 2020) - week 53 (3 January 2021 ) 12 May 2020 (week 20): changes in protocol, case definitions and data collection tool

Fig. 2 Prevalence of COVID-19 cases per 1000 residents and COVID-19 cases absent from work per 1000 staff members

\section{COVID-19 deaths among nursing home residents}

During the entire study period (11 March 2020 to 3 January 2021), 11,369 (possible or confirmed) COVID19 deaths among $\mathrm{NH}$ residents were reported (6072 during W1, 150 during the interwave period and 5147 during W2): $76 \%$ died in the NHs and $24 \%$ died in hospital (22\% during W1, 45\% during the interwave period and $27 \%$ during W2).

The 11,369 deaths among NH residents represents 57\% of all COVID-19 deaths reported in Belgium during this period ( $n=19,847)$. The deaths of NH residents accounted for $63 \%$ of all COVID-19 deaths in W1, 48\% in the interwave period, and 52\% in W2. Peaks of COVID-19 deaths among NHs residents were reached in week $15(n=1433)$ in W1 and in week $46(n=703)$ in W2. Most deaths $(73 \%)$ occurred in laboratory confirmed cases (55\% during W1,
73\% during the interwave period, and 95\% during W2). The number of COVID-19 deaths among NH residents is presented by week in Fig. 5.

The median number of reported COVID-19 deaths per $\mathrm{NH}$ was 7 (IQR $3-13)$. Overall, $77 \%$ of the NHs $(n=1188)$ reported at least 1 COVID-19 death, 68\% $(n=1044)$ at least 2 deaths, $50 \%(n=774)$ at least 5 deaths and $28 \%$ ( $n=433)$ at least 10 deaths. The median age of the $\mathrm{NH}$ residents that died of COVID-19 during the study period was 88 years (IQR 83-92 years, 61\% females).

\section{Discussion}

Main results

While the applied surveillance was intended in the first place to serve the RHA to manage the crisis and mitigate the epidemic, it allowed us to quantify the COVID-19 


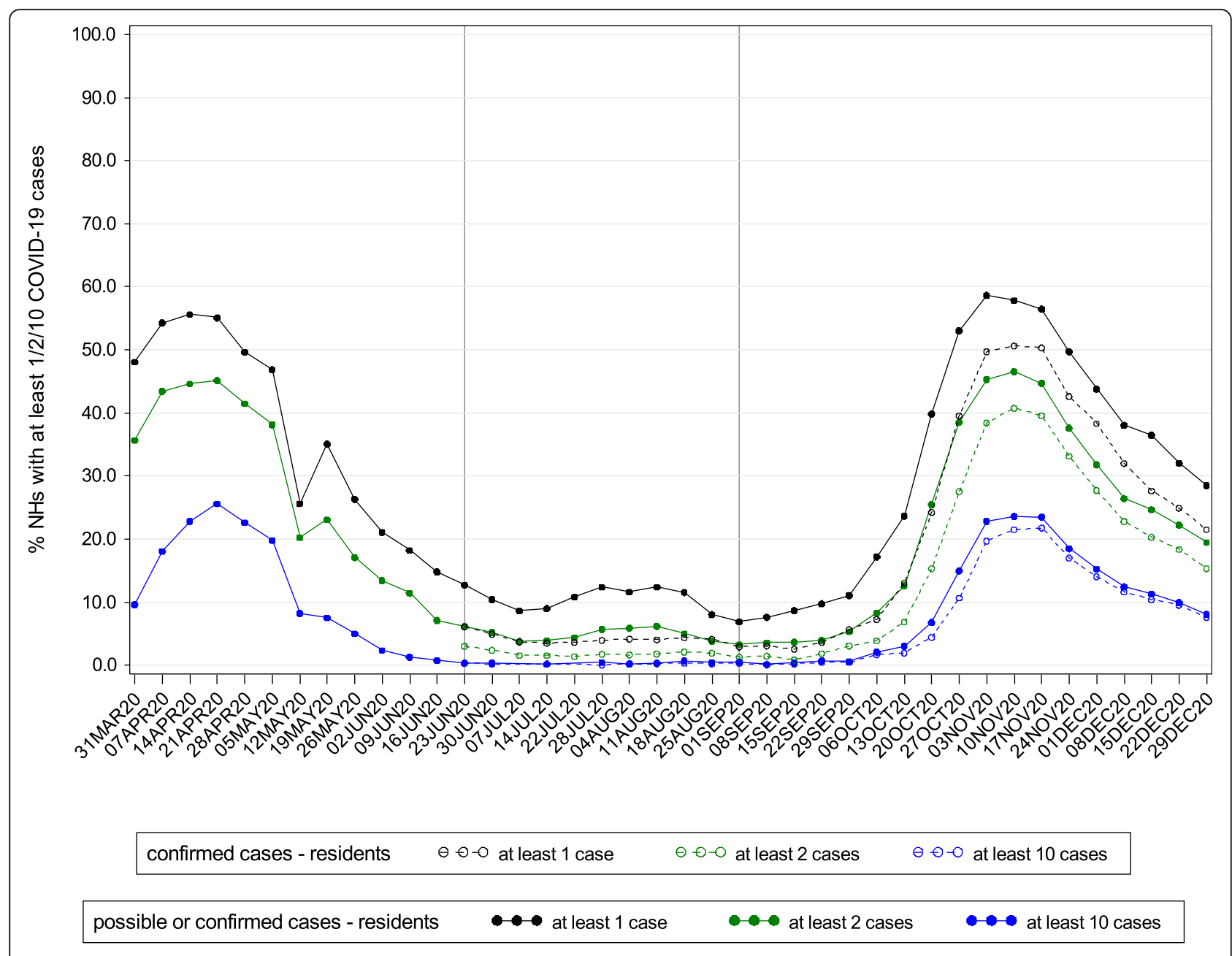

Results based on prevalence, estimated on Tuesdays. Wave 1: week 14 (30 March 2020) - week 25 (21 June 2020); interwave period: week 26 (22 June 2020) - week 35 (30 August 2020), Wave 2: week 36 (31 August 2020) - week 53 (3 January 2021) 12 May 2020 (week 20): changes in protocol, case definitions and data collection tool

Fig. 3 Percentage of participating nursing homes that declared at least 1/2/10 possible/confirmed COVID-19 cases among residents by week

pandemic in Belgian NHs prior to the vaccination campaign. Unfortunately and as notified in many countries, Belgian NHs were severely hit by this pandemic. Only a few NHs (3\%) never reported any possible or confirmed COVID-19 case among residents. Most NHs (82\%) reported cases in both waves. Moreover, absenteeism data show that a considerable number of NHs suffered from staff shortage due to COVID-19 infections among staff members. This is an underestimation of the real absenteeism as other reasons for absence such as chronic conditions like burn-out were not taken into account.

From 12 March 2020 onwards, no visitors were allowed in the NHs for at least 40 days. Although this measure was implemented in the very beginning of the pandemic, it could not avoid the spread of SARS-CoV-2 in the NHs during W1. This suggests that the virus was introduced in this period in many NHs by staff. Asymptomatic cases of staff might have played a role here [20]. Only since 16 April (due to the limited supply of masks in the beginning of the pandemic), the use of surgical masks became recommended for contacts with residents. The initial lack of personal protective equipment (PPE) and infection prevention and control (IPC) training suggests that the majority of cases in W1 were healthcareassociated. Between the end of April and half of May (depending on the regional health authority), a limited number of visitors was allowed again and this remained so until the end of the study period. During the study period, IPC measures of different kind have been implemented at regional and local level (e.g. quarantine measures, cohorting of (possible) cases among residents and staff, use of additional PPE, preventive and rapid testing, 
Table 3 Number of nursing homes reporting at least 1/2/10 COVID-19 cases among residents and at least 10/20/50\% of staff absent due to COVID-19 at one point in time

\begin{tabular}{|c|c|c|c|c|c|c|c|c|c|c|}
\hline \multirow[t]{2}{*}{ Nursing homes $(n=1542)$} & \multicolumn{2}{|c|}{ Wave 1} & \multicolumn{2}{|c|}{ Interwave period } & \multicolumn{2}{|c|}{ Wave 2} & \multicolumn{2}{|c|}{ All periods } & \multicolumn{2}{|c|}{ Wave 1 and $2^{a}$} \\
\hline & $N$ & $\%$ & $n$ & $\%$ & $\bar{N}$ & $\%$ & $\bar{n}$ & $\%$ & $\bar{n}$ & $\%$ \\
\hline \multicolumn{11}{|l|}{ Residents } \\
\hline$\geq 1$ possible or confirmed case & 1355 & 87.9 & 699 & 45.3 & 1407 & 91.2 & 1495 & 97.0 & 1269 & 82.3 \\
\hline$\geq 2$ possible or confirmed cases & 1147 & 74.4 & 376 & 24.4 & 1277 & 82.8 & 1447 & 93.8 & 982 & 63.7 \\
\hline$\geq 10$ possible or confirmed cases & 603 & 39.1 & 35 & 2.3 & 784 & 50.8 & 1140 & 73.9 & 250 & 16.2 \\
\hline$\geq 1$ confirmed case & & & 298 & 19.3 & 1233 & 80.0 & & & & \\
\hline$\geq 2$ confirmed cases & & & 134 & 8.7 & 1065 & 68.5 & & & & \\
\hline$\geq 10$ confirmed cases & & & 19 & 1.2 & 681 & 44.2 & & & & \\
\hline \multicolumn{11}{|l|}{ Staff absent from work ${ }^{b}$} \\
\hline$\geq 10 \%$ (possible or confirmed cases) & 110 & 7.1 & 45 & 2.9 & 703 & 45.6 & 784 & 50.8 & 41 & 2.7 \\
\hline$\geq 20 \%$ (possible or confirmed cases) & 28 & 1.8 & 9 & 0.6 & 290 & 18.8 & 314 & 20.4 & 8 & 0.5 \\
\hline$\geq 50 \%$ (possible or confirmed cases) & 4 & 0.3 & 1 & 0.1 & 35 & 2.3 & 38 & 2.5 & 1 & 0.1 \\
\hline$\geq 10 \%$ (confirmed cases) & & & 19 & 1.2 & 570 & 37.0 & & & & \\
\hline$\geq 20 \%$ (confirmed cases) & & & 4 & 0.3 & 212 & 13.7 & & & & \\
\hline$\geq 50 \%$ (confirmed cases) & & & 0 & 0 & 15 & 1.0 & & & & \\
\hline
\end{tabular}

During wave 1 as well as wave 2, not cumulative

${ }^{\mathrm{b}}$ Data only available since 12 May 2020 (week 20) for the whole country

Results based on prevalence.

Wave 1: week 14 (30 March 2020) - week 25 (21 June 2020); interwave period: week 26 (22 June 2020) - week 35 (30 August 2020 ), Wave 2: week 36 (31 August 2020) - week 53 (3 January 2021).

ventilation). Each RHA provided detailed instructions for NHs how to deal with COVID-19, but also human resources support initiatives, pro-active calling centres and professional education support. Depending on the available resources and based on the results of the surveillance, outbreak investigations were set up for the largest outbreaks and in NHs with the highest need for local support. Due to important regional and local differences over time it is difficult to assess the impact of the different mitigation measures taken. We can nevertheless reasonably assume that without these measures, W2 would have been much worse [21].

In both waves, the peak in prevalence occurred two weeks after the peak in incidence numbers. On 12 May, it had been clarified in the protocol that a confirmed case remained a case for at least 14 days (or longer depending on symptoms). The cumulative incidence of possible/confirmed cases among residents during W2 was almost twice as high compared to the end of W1, giving the impression that W2 was even worse than W1. One should be careful when comparing these waves. In the beginning of $\mathrm{W} 1$, extensive and systematic testing of possible cases in $\mathrm{NHs}$ was not possible as free tests were essentially reserved for hospitalized patients. When it became clear that many NHs reported high COVID-19 mortality rates and more tests became available, a massive testing campaign was set up between 8 April and 18 May 2020. This cross-sectional mass testing revealed that about $75 \%$ of those that tested positive (residents as well as staff) were asymptomatic at the moment of testing [20]. After this campaign, screening of all residents continued in the context of outbreak investigations, which had an impact on the results. Moreover, over time, NH staff became more familiar with the surveillance, leading possibly to better data registration and quality. Additionally, incidence data were missing for Wallonia in W1, which may have introduced selection bias. All these reasons explain why the results for W2 give a more complete picture and are more robust than those for W1. Nevertheless, despite enough PPE being available in W2 (in contrast with W1), still a high number of COVID-19 cases were reported.

Relatively more residents were hospitalised in W2 as compared to W1. It should be noted that information on residents that refused to be admitted to the hospital and residents that were refused by the hospital due to capacity issues is missing. Moreover, in the beginning of the epidemic, the geriatric society advised openly that residents with COVID-19 should only be referred to a hospital if they would substantially benefit from this hospitalization. Hence, the number of hospitalizations of residents might not be the best indicator to evaluate the severity of the infection. The number of deaths can be considered as a more stable indicator. With $57 \%$ of the COVID-19 deaths in 2020 being NH residents, this population (only $1.1 \%$ of the total population) was the 


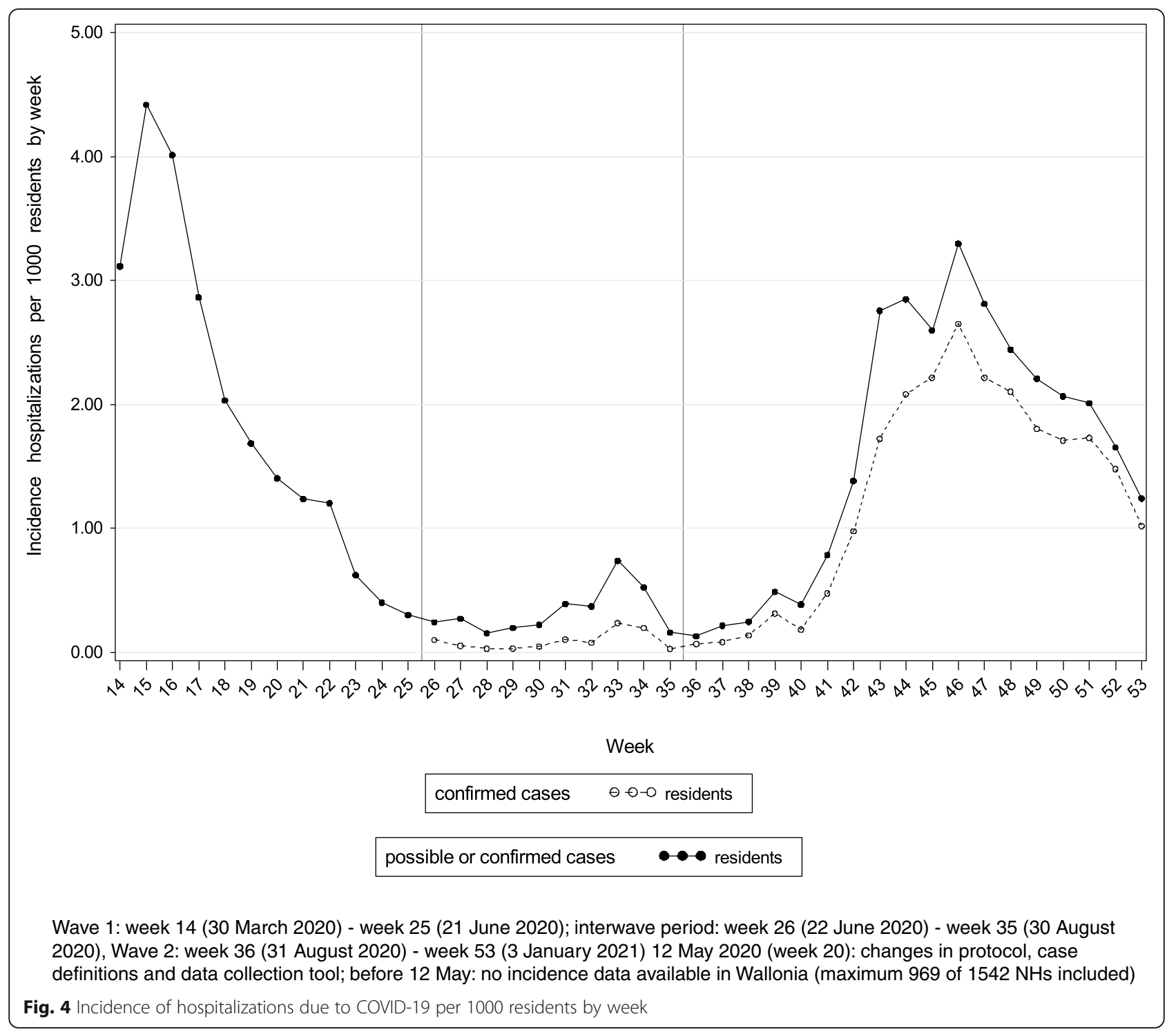

main group affected. At the beginning of the pandemic, Belgium was acknowledged for its excellent registration including possible COVID-19 deaths in the COVID-19 death statistics, in contrast to many other countries who reported only confirmed cases or even only hospital deaths [7]. The number of deaths of $\mathrm{NH}$ residents in W1 was not exceeded in W2 (if counted until 3 January). W2 lasted longer than W1, but peaked less high in terms of deaths. In November 2020, the increase of COVID-19 cases in LTCFs in Belgium and other European countries led to a rapid risk assessment of ECDC. This assessment indicated that several countries were suffering from a second COVID-19 wave in this setting with many fatal cases [11]. Since the NH setting and population can be highly variable across countries, comparing with other countries is difficult.
Since July 2020 (sufficient testing capacity) the 7-day incidence of confirmed COVID-19 cases among NH residents shows a similar (but higher) trend as this incidence in the community. In the community, a sharp increase was observed in week 40 (end of September) [22], whereas in NHs this was observed in week 41. Both the possible introduction by staff (and visitors) and the week delay in the increase of the trend, suggest that the virus was, again in W2, silently introduced from the community. Similar findings have been reported in other countries (UK, Canada, United States) [23-25]. On top, the fact that $51 \%$ of the NHs reported a prevalence of at least ten possible/confirmed cases at one moment in time during W2, suggests that once the virus was introduced in the facility, it was still difficult to prevent spread and outbreaks. 


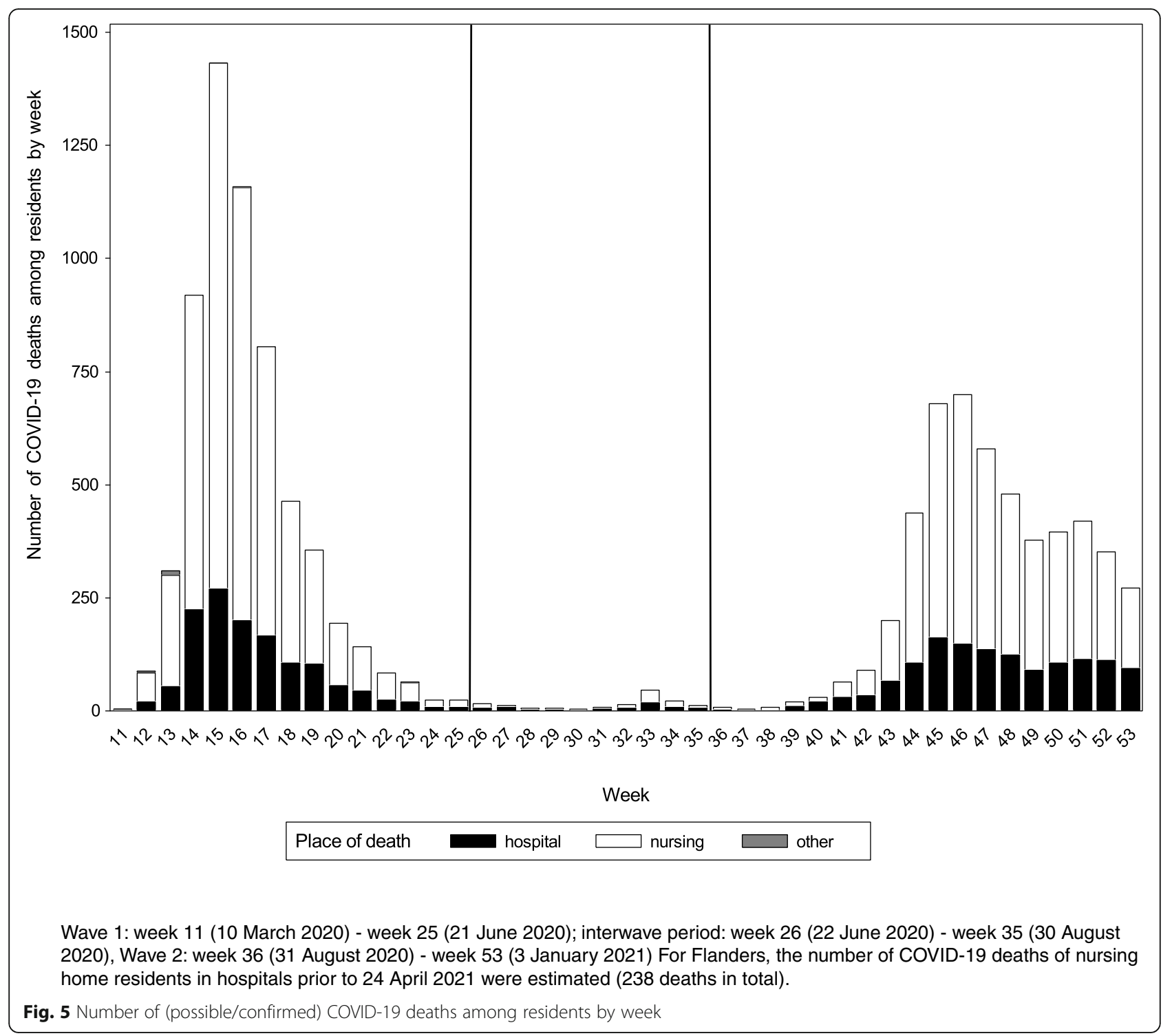

\section{Strengths and limitations}

The Belgian COVID-19 surveillance in NHs has been set up very quickly in the context of the pandemic, leveraging the existing experience with infectious disease surveillance in hospitals and LTCFs. Only 14 days after the first COVID-19 death, the surveillance was operational in all regions. The surveillance is part of the national action plan for COVID-19. Several complementary surveillances (e.g. COVID-19 surveillance of confirmed cases in the general population, of cases admitted to Belgian hospitals [26] and of mortality [7]) were put in place and data are linked where possible .

Including possible cases permitted to detect a possible outbreak early and intervene quickly with focussed testing (maximal five tests per $\mathrm{NH}$ when an outbreak was suspected in the first months of the epidemic), assistance with PPE, extra staff, psychosocial support and infectious disease management courses. Looking at lab-confirmed cases only would have led to an important underestimation of the incidence/prevalence, especially in the beginning of the COVID-19 crisis. However, it should be taken into account that possible cases might have included respiratory tract infections other than COVID-19 and might have led to an overestimation of the incidence/prevalence of COVID-19.

A high weekly participation rate (median 95\%) was reached over the whole study period. Downscaling the registration in some regions from daily to at least once a week in the beginning of July ensured that it remained feasible for all NHs to keep registering data. By collecting also denominator data of residents and staff, relative numbers could be presented making the interpretation over time with varying participation rates easier. A good cooperation between the RHA and Sciensano made it 
possible to perform analyses on a national level and to visualize the COVID-19 epidemic in Belgian NHs. Since the beginning of the pandemic, detailed weekly reports of the surveillance were made available to the authorities and general public [27]. The COVID-19 surveillance in Belgian NHs has been used as an example in ECDC guidelines [15].

The surveillance also has its limitations. Firstly, as mentioned earlier, the surveillance was set up very quickly in the context of the pandemic by the different RHA, independently from each other. Changes in the protocol, case definitions, data collection tools and variables to be collected were necessary during the first months to respond to the evolving insights in this emerging crisis and to harmonise the data collection. Therefore data of W1 are less robust. Secondly, due to the speed with which this surveillance was set up, there was no time for extensive testing of the different tools. In addition, $\mathrm{NH}$ staff were not familiar nor trained to collect surveillance data. Especially in this older population with often vague complaints, it might have been difficult to identify possible cases based on symptoms. Moreover, the surveillance is based on aggregated and not casebased data (except for deaths), which limits the possibilities for data validation (e.g. identification of possible double reported cases, missing cases or delayed reporting), but also for the interpretation of the results. Despite these limitations, it was possible to monitor the epidemic guiding the policy makers in their decisions. However, for more in-depth analyses (e.g. cluster analyses) and to investigate other determinants that played a role (e.g. comorbidities), a case-based registration would be needed. Finally, analyses were limited to the first and second COVID-19 wave and only performed at national level. In future studies, an impact analysis of the vaccination campaign (which started in January 2021) and regional differences could be considered.

\section{Conclusions}

The COVID-19 surveillance in Belgian NHs, essential to guide policy makers, allowed us to map the COVID-19 epidemiology in this setting, despite the limitations of aggregated data and changes in the protocol over time. A high weekly participation rate was achieved throughout the entire study period. The results enabled the RHA to detect a possible outbreak early and to intervene quickly with targeted testing, IPC measures, extra staff and support.

Unfortunately, NHs in Belgium were severely hit by COVID-19, both in W1 and W2, with many fatal cases. W2 lasted longer than W1, but peaked less high in terms of deaths. The measure of not allowing visitors, which was implemented in the very beginning of the pandemic, did not prevent the spread of SARS-CoV-2 in this setting. The virus was probably introduced from the community by staff (or visitors) and once it was introduced, it was difficult to prevent healthcare-associated outbreaks. The majority of NHs reported cases in both waves, indicating that a first outbreak does not guarantee protection for subsequent outbreaks.

\section{Abbreviations}

CT: computed tomography; ECDC: European Centre for Disease Prevention and Control; IPC: infection prevention and control; IQR: interquartile range; LTCF: long-term care facility; NH: nursing home; PCR: polymerase chain reaction; PPE: personal protective equipment; $\mathrm{RHA}$ : regional health authorities; SARS-CoV-2 virus: severe acute respiratory syndrome coronavirus2; W1: first wave; W2: second wave

\section{Supplementary Information}

The online version contains supplementary material available at https://doi. org/10.1186/s13690-022-00794-6.

Additional file 1. Surveillance COVID-19 in Belgian nursing homes (2020), overview data collection in the different regions

Additional file 2. Surveillance COVID-19 in Belgian nursing homes (2020), summary of the validation rules for data cleaning

Additional file 3. Weekly participation rate of all Belgian nursing homes (NHs, $n=1542$ ) per period

\section{Acknowledgements}

We sincerely would like to thank all NH staff for their continuous commitment to register data for this surveillance, which was essential for the management and follow-up of the COVID-19 crisis in this setting. We also would like to thank the regional health authorities for setting up this surveillance, implementing it on a daily basis, managing the crisis and sharing their data with Sciensano. In addition, our gratitude goes towards many colleagues within Sciensano who helped set up the surveillance, compiled and report the national data on a daily, weekly or monthly basis (among others the mortality team, hospital team, reporting team, surveillance team, vaccination team).

\section{Authors' contributions}

EV and SD drafted the manuscript. EV, SD, KL, LIP, El, MC and BC were responsible for setting up the national protocol and performed the data merging and analyses on national level. RM, LV, ED, AK, NH, JMF, DD, SH were involved in the surveillance and data collection on region level. FH and $\mathrm{KP}$ are part of the team that led the mortality surveillance in nursing homes and other settings. BD, JRG and AH helped with the analyses and the reporting to the authorities and public. All authors contributed to commenting on and revising the manuscript. All authors have seen and approved the final manuscript as submitted.

\section{Funding}

This surveillance was co-organised by the Healthcare-associated infections and Antibiotic resistance service (www.nsih.be) and the mortality team (BEMOMO) from Sciensano, partially funded by the federal (Belgian Antibiotic Policy Coordination Committee) and the regional health authorities.

\section{Availability of data and materials}

The datasets used and/or analysed during the current study are available from the corresponding author on reasonable request.

\section{Declarations}

Ethics approval and consent to participate

The study protocol was approved by the Ghent University ethical committee (23/10/2020, BC-08065).

Consent for publication

Not applicable. 


\section{Competing interests}

None declared.

\section{Author details}

'Department of Epidemiology and public health, Sciensano, Brussels, Belgium. ${ }^{2}$ Department of Veterinary Public Health and Food Safety, Ghent University, Merelbeke, Belgium. ${ }^{3}$ Department of Infectious Disease Prevention and Control, Common Community Commission, Brussels-Capital Region, Brussels, Belgium. ${ }^{4}$ Iriscare - Brussels public agency for health and social care, Brussels, Belgium. ${ }^{5}$ Department of Welfare, Public Health and Family, Government of Flanders, Brussels, Belgium. ${ }^{6}$ Agency for Care and Health, Infection Prevention and Control, Government of Flanders, Brussels, Belgium. ${ }^{7}$ Direction de la recherche, de la statistique et de la veille des politiques, Agence pour une Vie de Qualité (AVIQ), Charleroi, Belgium. ${ }^{8}$ Ministerium der Deutschsprachigen Gemeinschaft, Eupen, Belgium. ${ }^{9}$ Faculty of Medicine, Université libre de Bruxelles (ULB), Brussels, Belgium.
\end{abstract}

Received: 18 October 2021 Accepted: 7 January 2022

Published online: 29 January 2022

\section{References}

1. Hopkins, J University - Coronavirus Resource Center. COVID-19 Dashboard by the Center for Systems Science and Engineering (CSSE) at Johns Hopkins University (JHU). 2021 [Assessed 14 Jan 2021]. Available from: https://corona virus.jhu.edu/map.html.

2. Spiteri G, Fielding J, Diercke M, Campese C, Enouf V, Gaymard A, et al. First cases of coronavirus disease 2019 (COVID-19) in the WHO European region, 24 January to 21 February 2020. Euro Surveill. 2020;25(9):2000178. https:// doi.org/10.2807/1560-7917.ES.2020.25.9.2000178

3. Wu C, Chen X, Cai Y, Xia J, Zhou X, Xu S, et al. Risk factors associated with acute respiratory distress syndrome and death in patients with coronavirus disease 2019 pneumonia in Wuhan. China JAMA Intern Med. 2020;180(7): 934-43. https://doi.org/10.1001/jamainternmed.2020.0994.

4. Onder G, Rezza G, Brusaferro S. Case-fatality rate and characteristics of patients dying in relation to COVID-19 in Italy. JAMA. 2020;323(18):1775-6. https://doi.org/10.1001/jama.2020.4683.

5. Peeters I, Vermeulen M, Bustos Sierra N, Renard F, Van der Heyden J, Scohy A, et al. Surveillance of COVID-19 mortality in Belgium, epidemiology and methodology during $1^{\text {st }}$ and $2^{\text {nd }}$ wave (March 2020-14 February 2021). Sciensano: Brussels; 2021. [Assessed 9 Sep 2021]. Available from: https:// covid-19.sciensano.be/nl/covid-19-epidemiologische-situatie

6. ECDC Public Health Emergency Team, Danis K, Fonteneau L, Georges S, Daniau C, Bernard-Stoecklin S, et al. High impact of COVID-19 in long-term care facilities, suggestion for monitoring in the EU/EEA, May 2020. Euro Surveill. 2020;25(22):2000956.

7. Renard F, Scohy A, Van der Heyden J, Peeters I, Dequeker S, Vandael E, et al. Establishing an ad hoc COVID-19 mortality surveillance during the first epidemic wave in Belgium, 1 March to 21 June 2020. Euro Surveill. 2021; 26(48).

8. ECDC. European Centre for Disease Prevention and Control COVID-19 Situation Dashboard 2021 [Assessed 09 Dec 2021]. Available from: https://qa p.ecdc.europa.eu/public/extensions/COVID-19/COVID-19.htm|\#globaloverview-tab

9. Intermutualistisch Agentschap (IMA-AIM). Statistieken ouderenzorg: woonzorgcentrum 65- plussers 2018 - België [Assessed 16 Sep 2021]. Available from: https://atlas.ima-aim.be/databanken/?rw=1\&lang=nl.

10. Spasova S, Baeten R, Coster S, Ghailani D, Pena-casas R, Vanhercke B. Challenges in long-term care in Europe - A study of national policies. Brussels: European commission. 2018 [Assessed 13 Sep 2021]. Available from: https://ec. europa.eu/social/main.jsp?langld=en\&catld=89\&newsld=9185

11. European Centre for Disease Prevention and Control (ECDC). Rapid risk assessment: Increase in fatal cases of COVID-19 among long-term care facility residents in the EU/EEA and the UK. 19 November 2020. ECDC, Stockholm. 2020 [Assessed 13 Sep 2021]. Available from: https://www.ecdc europa.eu/sites/default/files/documents/Increase-fatal-cases-of-COVID-19-a mong-long-term-care-facility-residents.pdf.

12. European Centre for Disease Prevention and Control (ECDC). Point prevalence survey of healthcare-associated infections and antimicrobial use in European long-term care facilities. April-May 2013. ECDC, Stockholm. 2014 [Assessed 13 Sep 2021]. Available from: https://www.ecdc.europa.eu/
sites/default/files/media/en/publications/Publications/healthcare-associatedinfections-point-prevalence-survey-long-term-care-facilities-2013.pdf.

13. Utsumi M, Makimoto K, Quroshi N, Ashida N. Types of infectious outbreaks and their impact in elderly care facilities: a review of the literature. Age Ageing. 2010;39(3):299-305. https://doi.org/10.1093/ageing/afq029.

14. McMichael TM, Currie DW, Clark S, Pogosjans S, Kay M, Schwartz NG, et al. Epidemiology of Covid-19 in a long-term Care Facility in King County. Washington N Engl J Med. 2020;382(21):2005-11. https://doi.org/10.1056/ NEJMoa2005412.

15. European Centre for Disease Prevention and Control (ECDC). Technical report: Surveillance of COVID-19 at long-term care facilities in the EU/EEA. ECDC, Stockholm. 2020 [Assessed 13 Sep 2021]. Available from: https:// www.ecdc.europa.eu/sites/default/files/documents/covid-19-long-term-carefacilities-surveillance-guidance.pdf.

16. Dequeker $\mathrm{S}$, Latour K, Islamaj $\mathrm{E}$, Int Panis L, Callies M, Catteau L, et al. COVID-19 surveillance in residential institutions: Protocol version 4.2. Sciensano, Brussels. 2021; [Assessed 13 Sep 2021]. Available from: https:// www.sciensano.be/sites/default/files/20210111_protocol_covid-19_surveilla nce_in_residential_institutions_v4.2_final.pdf.

17. Vander Stichele $\mathrm{RH}$, de Voorde Carine V, Elseviers M, Verrue C, Soenen K, Mike $\mathrm{S}$, et al. Geneesmiddelengebruik in de Belgische rusthuizen en rust- en verzorgingstehuizen. Federaal Kenniscentrum voor de Gezondheidszorg (KCE). Brussel. 2006; [Assessed 13 Sep 2021]. Available from: https://kce.fgov. $\mathrm{be/nl/geneesmiddelengebruik-in-de-belgische-rusthuizen-en-rust-en-}$ verzorgingstehuizen.

18. European Observatory on Health Systems and Policy Monitor. The Health Systems and Policy Monitor: Health Systems in Transition (HiT) profile of Belgium. 2021 [Assessed 13 Sep 2021]. Available from: https://www.hspm. org/countries/belgium25062012/livinghit.aspx?Section=5.8\%20Long\%2 Oterm\%20care\&Type=Section.

19. Covid-19 case definition and indication for tests. Sciensano, Brussels. 2021; [Assessed 3 Mar 2021]. Available from: https://covid-19.sciensano.be/nl/ covid-19-gevalsdefinitie-en-testing.

20. Hoxha A, Wyndham-Thomas C, Klamer S, Dubourg D, Vermeulen M, Hammami N, et al. Asymptomatic SARS-CoV-2 infection in Belgian longterm care facilities. Lancet Infect Dis. 2021;21(4):e67. https://doi.org/10.1016/ S1473-3099(20)30560-0.

21. Flaxman S, Mishra S, Gandy A, Unwin HJT, Mellan TA, Coupland H, et al. Estimating the effects of non-pharmaceutical interventions on COVID-19 in Europe. Nature. 2020;584(7820):257-61. https://doi.org/10.1038/s41586-02 0-2405-7.

22. Belgian Dashboard - COVID-19 epidemiological situation. Sciensano, Brussels. 2021 [Assessed 27 Mar 2021]. Available from: https://epistat.wiv-isp. be/covid/covid-19.html.

23. Malikov K, Huang Q, Shi S, Stall NM, Tuite AR, Hillmer MP. Temporal associations between community incidence of COVID-19 and nursing home outbreaks in Ontario. Canada J Am Med Dir Assoc. 2021;22(2):260-2. https:// doi.org/10.1016/j.jamda.2020.12.011.

24. Chudasama DY, Milbourn H, Nsonwu O, Senyah F, Florence I, Cook B, et al. Penetration and impact of COVID-19 in long term care facilities in England: population surveillance study. Int J Epidemiol. 2021:dyab176. https://doi. org/10.1093/ije/dyab176.

25. Bagchi S, Mak J, Li Q, Sheriff E, Mungai E, Anttila A, et al. Rates of COVID-19 among residents and staff members in nursing homes - United States, may 25-November 22, 2020. MMWR Morb Mortal Wkly Rep. 2021;70(2):52-5. https://doi.org/10.15585/mmwr.mm7002e2.

26. Van Goethem N, Vilain A, Wyndham-Thomas C, Deblonde J, Bossuyt N, Lernout T, et al. Rapid establishment of a national surveillance of COVID-19 hospitalizations in Belgium. Arch Public Health. 2020;78(1):121. https://doi. org/10.1186/s13690-020-00505-z.

27. Weekly report COVID-19 surveillace in nursing homes. Sciensano, Brussels 2021 [Assessed 19 Mar 2021]. Available from: https://covid-19.sciensano.be/ sites/default/files/Covid19/COVID-19_Surveillance_WZC.pdf.

\section{Publisher's Note}

Springer Nature remains neutral with regard to jurisdictional claims in published maps and institutional affiliations. 